Trop. Anim. Hith Prod. (1975) 7, 61

\title{
Some Accepted Titles Awaiting Publication
}

Evaluation of the field complement fixation test in the diagnosis and control of contagious bovine pleuropneumonia.

Copper status in livestock, pasture and soil in Western Sudan.

Experimental infections of cattle with F. gigantica: numbers of parasites recovered after varying periods of infection.

The route of infection of buffalo calves by Toxocara (Neoascaris) vitulorum.
The establishment of an experimental field population of Theileria parvainfected ticks.

Seychelles.

Serum proteins, blood and plasma volumes in experimental $T$. vivax infections of sheep and goats.

Economic losses from foot and mouth disease: a case study on a pig farm in Colombia.

\section{ERRATUM}

The Map on page 196 of the last issue of Tropical Animal Health and Production(Vol. 6 No. 4) was incorrectly placed upside down. The Editor and Publishers apologise for any inconvenience caused. 